\title{
A Survey of Group Practice in the United States, 1965
}

BRUCE E. BALFE, M.A.

QINCE 1945, the group practice of medicine $\checkmark$ has become a major organizational factor in the health care delivery system. In the past several years, the concept of group practice has come under renewed scrutiny as a means of alleviating some problems of the health care system, particularly in regard to manpower shortages and the cost of medical care. Because the solutions of these two related problems are vital to the medical profession and to the public, trends and developments in group practice should be carefully watched.

One of the prerequisites to intelligent analysis of the future of group practice is sound data on the number and characteristics of groups and group physicians. In 1946 and 1959, the Public Health Service conducted surveys of group practice to provide such data. In 1965, the American Medical Association, recognizing the need for more up-to-date information, conducted a similar survey. The purposes of the AMA project were twofold: to provide a statistical profile of group practice as of 1965 and to compare the results with those of the group practice surveys of 1946 and 1959 in order to identify trends in the nature and magnitude of group practice.

Mr. Balfe is research associate in the department of survey research of the American Medical Association, Chicago, Ill. This paper summarizes the results of a survey of medical groups that the AMA conducted in November 1965. The detailed tabulations of the results were published in "Survey of Medical Groups in the U.S., 1965," by Balfe and M. E. McNamara, American Medical Association, Chicago, 1968.
The success of the survey in achieving these two objectives provides a basis upon which the various definitions and concepts of group practico can be evaluated. In addition, the data provide a new base upon which future surveys can be designed.

This survey was not designed to provide an in-depth analysis of group practice from a functional viewpoint. Rather, it was designed to provide a thorough description of its characteristics. In the publication upon which this paper is based, we expressly avoided making judgments or providing reasons for the observations reported. Such judgments in a descriptive publication only open the door to controversy over interpretation and tend to overshadow the validity of the data presented. Hence we decided that the data should be presented in a purely descriptive fashion, to stand or fall on their own merit, free from the complications of interpretive value judgments.

\section{Survey Method}

A listing of medical groups in the United States was compiled and published in November 1959 by the Council on Medical Service of the American Medical Association. This list has since been maintained and updated with information received from annual surveys of physicians conducted by the AMA and from other sources.

In November 1965, the 5,838 medical groups listed in AMA records were sent a questionnaire soliciting information on their size, geographic location, form of organization, method of in- 
come distribution, specialty composition, and the allied health personnel which they employed. A 60 percent response was received from this first mailing. In March and July of 1966, those groups which had not responded previously were sent followup letters and questionnaires. The two followup mailings resulted in a $\mathbf{9 0 . 9}$ percent overall response.

Of the 5,838 medical organizations to which questionnaires were originally mailed, 529 either did not meet the definition of group practice used in this survey, had been dissolved, or represented duplicates in the response, leaving an effective population of 5,309 groups. The 1,020 nonrespondents consisted of 31 groups which indicated a desire to be excluded from the survey and 989 which did not respond at all. The remaining 4,289 groups which constituted the usable response represented 80.8 percent of the total number of medical organizations recorded by the AMA Physicians Records Service which met the definition of a group.

Definitions. The term "group practice" covers a variety of meanings in regard to organizational arrangements, number of physicians and fields of practice required, and methods of distributing income and expense among members. The following definition was used in this survey:

Group medical practice is the application of medical services by three or more full-time physicians formally organized to provide medical care, consultation, diagnosis, and/or treatment through the joint use of equipment and personnel, and with the income from medical practice distributed in accordance with methods previously determined by members of the group.

This definition differs from the one used for the AMA Physicians Records Service in that it specifies three or more full-time physicians irrespective of the number of part-time physicians. Most of the groups which were eliminated because "they did not meet the definition of a group" were respondent groups which were in the AMA master listing but had fewer than three full-time physicians. The definition used in the report was not included on the questionnaire or in any of the accompanying letters.

The 4,289 responding groups which met the definition were divided into three basic categories:

1. Single specialty groups. Medical groups
Table 1. Number and percent of groups and of full-time and part-time group physicians, by type of group

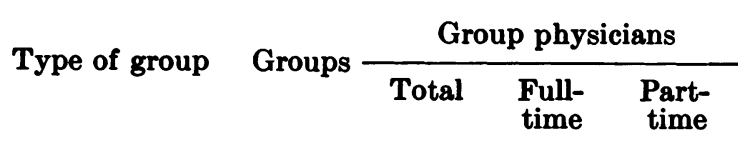

\begin{tabular}{|c|c|c|c|c|}
\hline \multirow{3}{*}{$\begin{array}{l}\text { All types--- } \\
\text { Single specialty }--- \\
\text { General practice } \\
\text { Multispecialty }\end{array}$} & \multicolumn{4}{|c|}{ Number } \\
\hline & $\begin{array}{r}4,289 \\
2,161 \\
651 \\
1,477\end{array}$ & $\begin{array}{r}28,381 \\
8,956 \\
2,284 \\
17,141\end{array}$ & $\begin{array}{r}25,452 \\
8,798 \\
2,252 \\
14,402\end{array}$ & $\begin{array}{r}2,929 \\
158 \\
32 \\
2,739\end{array}$ \\
\hline & \multicolumn{4}{|c|}{ Percent } \\
\hline $\begin{array}{l}\text { All types.-- } \\
\text { Single specialty } \\
\text { General practice-- } \\
\text { Multispecialty } \\
\text {---- }\end{array}$ & $\begin{array}{r}100.0 \\
50.4 \\
15.2 \\
34.4\end{array}$ & $\begin{array}{r}\text { 100. } 0 \\
31.6 \\
8.0 \\
60.4\end{array}$ & $\begin{array}{r}100.0 \\
34.6 \\
8.8 \\
56.6\end{array}$ & $\begin{array}{r}100.0 \\
5.4 \\
1.1 \\
93.5\end{array}$ \\
\hline
\end{tabular}

providing services in only one field of practice or major specialty, except groups composed exclusively of general practitioners.

2. General practice groups. Groups composed exclusively of general practitioners.

3. Multispecialty groups. Groups providing services in at least two fields of practice or major specialty.

Groups consisting exclusively of general practitioners and other single specialty groups are presented separately in order to allow flexibility in the interpretation and use of the data. The user of our statistics may therefore interpret the data to fit a variety of group practice definitions.

The 4,289 groups in this survey range in size from three physicians to more than $\mathbf{7 5 0}$ and include a wide range of distributions of full-time and part-time physicians in each type of group. Such a heterogenous population should be studied in terms of the differences that size makes in the characteristics of groups. The criterion used to determine the size of a group was the number of full-time physicians in the group. Hence, a group with three full-time and two part-time physicians is considered a three-man group. Neither the questionnaire nor the accompanying letter stated the criterion for establishing whether a physician was a full-time or part-time member. This omission precludes establishment of any accurate numerical full- 
time to part-time equivalent relationship. Therefore, in order to provide comparability, the size of groups was determined by the number of full-time physicians.

\section{Number and Size of Groups}

Of the total 4,289 groups in the survey, onehalf were single specialty, one-third were multispecialty and the remainder were general practice groups (table 1). There were 28,381 physicians who were either members of, or employed by, the 4,289 groups, including 246 dentists, all of whom were associated with multispecialty groups. Almost 90 percent of the physicians were engaged full time in group practice. Of the remaining 10 percent who were part-time group physicians, almost all practiced in multispecialty groups. Of the total 28,381 group physicians, 60.4 percent practiced in multispecialty groups, 31.6 percent in single specialty groups, and 8 percent in general practice groups.
The average size of groups responding to the survey was 6.6 physicians. Multispecialty groups, with an average of 11.6 physicians, were considerably larger than either single specialty groups, with an average of 4.1 physicians, or general practice groups, with an average of 3.5 physicians.

Three-fourths of the groups were in the size category of three to five physicians. The distribution by type of group shows that general practice groups and single specialty groups were highly concentrated in this size category; 96.8 percent of general practice groups and 88.6 percent of single specialty groups consisted of three to five physicians, while only half of the multispecialty groups were in this size category. On the other hand, 11.7 percent of the multispecialty groups reported 16 or more physicians per group; less than 1 percent of the single specialty and general practice groups combined fell into the larger size categories. Part-time physicians were more heavily concentrated in the

Table 2. Number and percent of groups and of group physicians, by type of group and size

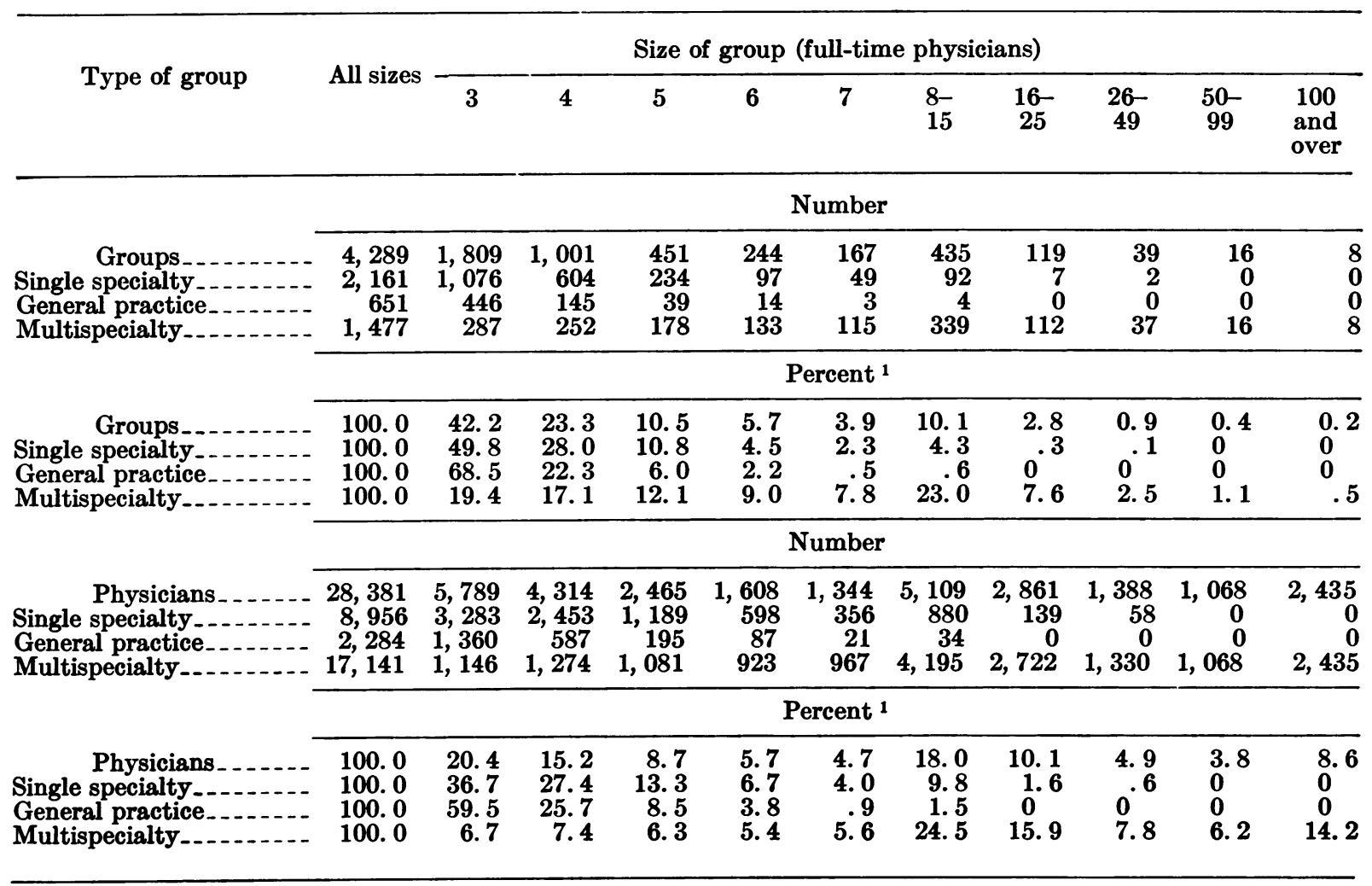

${ }_{1}^{1}$ Percentages may not add to 100.0 because of rounding. 
larger groups, since most of them were associated with multispecialty groups (table 2). There were eight groups with 100 or more physicians, accounting for 8.6 percent of total group physicians. The average size of groups in this category was 304 physicians.

In the survey, information was gathered on the size of each group during its initial year. Tabulation of the responses to this question by the current size of groups revealed that more than three-fourths have increased in size since formation. An additional 20 percent of the groups have not changed in size since formation, and only 2.7 percent decreased in size. These tabulations by initial and current size of groups were limited to the 3,593 groups in the 3 to 7 physicians size categories.

\section{Geographic Location}

Three census divisions, the East North Central, West North Central, and Pacific, contained more than half of the total groups and group physicians. New England had the smallest percentage of total groups ( 3.5 percent) and the smallest proportion of group physicians (3.8 percent). The East North Central Division had the highest percentage of groups (19.8 percent), while the highest percentage of group physicians (21.2 percent) were located in the Pacific Division (table 3).

There was considerable variation from the national average of 14.7 group physicians per 100,000 population. The highest ratios were in the West North Central Division with 24.9 group physicians per 100,000 population and in the Pacific Division with 24.8. The lowest was in the Middle Atlantic Division with 8.0.

The distribution of groups and group physicians within census divisions by type of group showed some interesting variations. In $\mathrm{New}$ England, almost three-fourths of the groups were single specialty, as compared with only slightly more than one-third in the West North Central Division. The most even distribution of groups was in the West North Central Division, in which 35.6 percent of the groups were single specialty, 24.1 percent were general practice, and 40.3 percent were multispecialty groups.

California, Texas, Now York, Ohio, and Illinois together accounted for more than one-third of all groups. There were no States without a group, but five States had fewer than 10 groups each. Thirteen States had 100 or more groups each, and eight States had more than 1,000 group physicians each. Alaska, Delaware, Maine, Vermont, and Wyoming each had fewer than 50.

The distribution of groups by size of community showed that single specialty groups tended to be concentrated in larger communities and general practice groups in smaller ones.

Table 3. Percentage distribution of groups and of group physicians, by census division and type of group

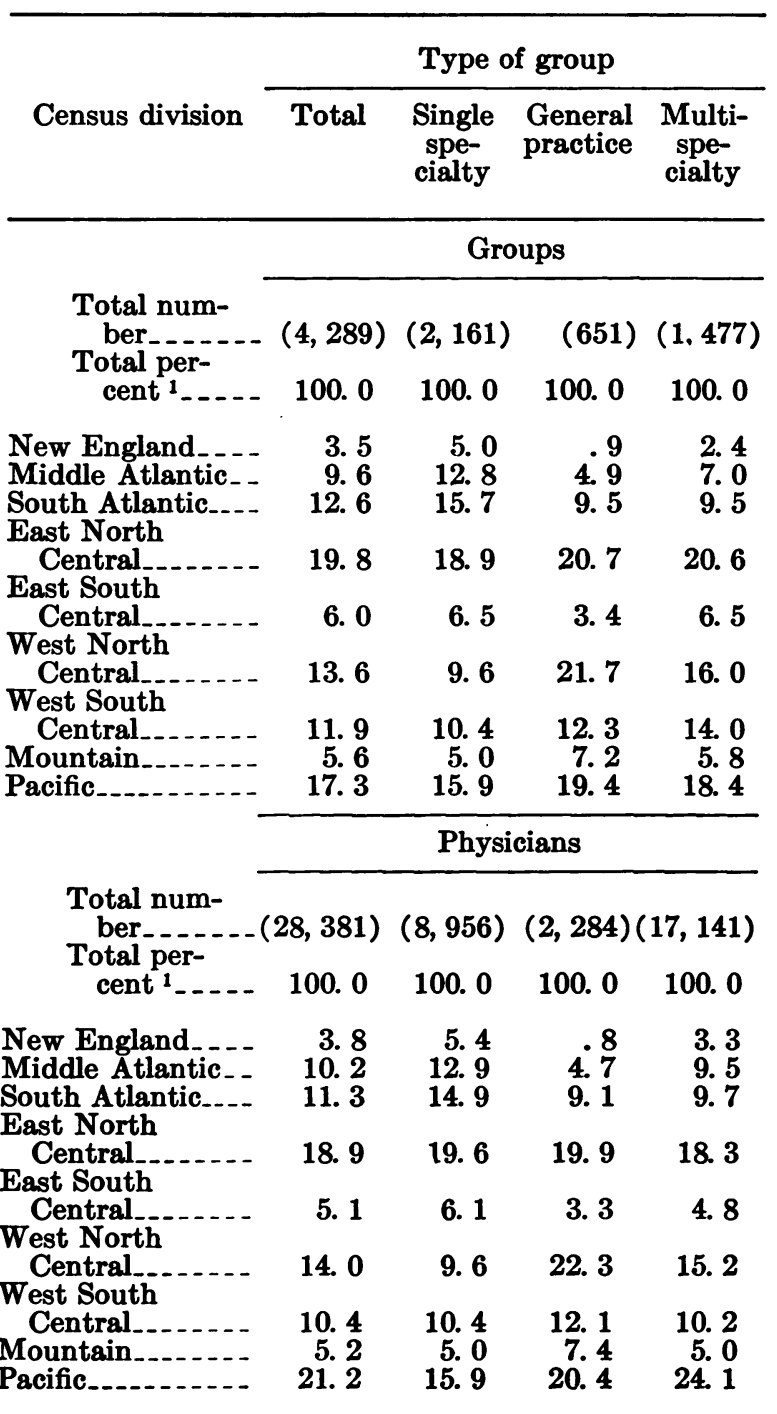

1 Percentages may not add to 100.0 because of rounding. 
Table 4. Percentage distribution of groups by form of organization and type of group

\begin{tabular}{|c|c|c|c|c|}
\hline \multirow{2}{*}{$\begin{array}{c}\text { Form of } \\
\text { organization }\end{array}$} & \multicolumn{4}{|c|}{ Type of group } \\
\hline & Total & $\begin{array}{c}\text { Single } \\
\text { spe- } \\
\text { cialty }\end{array}$ & $\begin{array}{l}\text { General } \\
\text { practice }\end{array}$ & $\begin{array}{l}\text { Multi- } \\
\text { spe- } \\
\text { cialty }\end{array}$ \\
\hline $\begin{array}{c}\text { Total num- } \\
\text { ber }- \\
\text { Total per- } \\
\text { cent }\end{array}$ & $\begin{array}{c}(4,289) \\
100.0\end{array}$ & $\begin{array}{c}(2,161) \\
100.0\end{array}$ & $\begin{array}{l}(651) \\
100.0\end{array}$ & $\begin{array}{c}(1,477) \\
100.0\end{array}$ \\
\hline $\begin{array}{l}\text { Single owner } \\
\text { Partnership } \\
\text { Corporation } \\
\text { Association } \\
\text { Foundation } \\
\text { Other } \\
\end{array}$ & $\begin{array}{r}3.0 \\
77.8 \\
8.1 \\
8.8 \\
.3 \\
2.0\end{array}$ & $\begin{array}{r}1.7 \\
79.9 \\
7.6 \\
8.9 \\
(1) \\
1.9\end{array}$ & $\begin{array}{r}3.5 \\
84.9 \\
4.5 \\
6.0 \\
0 \\
1.1\end{array}$ & $\begin{array}{r}4.8 \\
71.5 \\
10.3 \\
10.0 \\
.9 \\
2.5\end{array}$ \\
\hline
\end{tabular}

${ }^{1}$ Less than 0.1 percent.

One-third of the single specialty groups were in communities of 500,000 or more population. Almost three-fourths of the general practice groups, on the other hand, were in communities with populations of 50,000 or less. Multispecialty groups were about evenly divided between communities of less than 50,000 population (54.7 percent) and those with 50,000 or more (45.3 percent).

\section{Organization and Structure of Groups}

Respondents were asked to indicate the form of organization under which the group provides professional services. There were six choicessingle owner, partnership, corporation, association, foundation, and "other." Partnerships were by far the most popular form of organization, accounting for slightly more than threefourths of total groups. The next most prevalent form was the association, which represented 8.8 percent of total groups, followed by corporations, which accounted for 8.1 percent of the groups. Single owner groups accounted for 3.0 percent of all groups. Less than 1 percent of the groups were foundations (table 4).

Groups with 3 to 5 physicians comprised more than 60.0 percent each of the single owner groups, partnerships, corporations, and associations. Foundations were the only organizational form found predominantly in the larger sized categories. Four of the eight groups with 100 or more physicians were partnerships, one was a corporation, one was an association, and two were classified as "other."

Only groups with a predetermined method of distributing income among their members were counted as part of the usable response to this survey. Three methods of income distribution were reported-salary only, salary plus a share of net income, and share of net income only. The "share of net income only" category was further divided into equal shares and varying shares. Most of the groups (83.1 percent) reported "share of net income only" as the method of income distribution. Of the 3,563 groups which used this method, 44.5 percent distributed income equally among group members, and 55.5 percent used a method which distributed varying shares to different group physicians in accordance with some predetermined formula. Only 3.6 percent of the groups distributed income exclusively by salary, while 3.9 percent supplemented a basic salary with a system of sharing net income. The remaining 9.4 percent of the respondents either reported "other" for method of income distribution or did not answer the question.

\section{Specialties of Group Physicians}

General practitioners, internists, and general surgeons combined accounted for almost half of the total physicians in the survey. Group practice was found to be more popular among certain specialists than others. More than onefourth of the radiologists and anesthesiologists who were engaged in patient care practiced in groups (table 5). The specialists least inclined to practice in groups were psychiatrists and general practitioners. Certain specialists were found to be concentrated in multispecialty groups. At least three-fourths of the dermatologists, general surgeons, internists, ophthalmologists, otolaryngologists, and physiatrists in group practice were associated with multispecialty groups.

\section{Allied Health Personnel}

One of the advantages often attributed to group practice is more efficient use of allied health personnel to handle the routine medical procedures and paperwork of medical practice, 
thus freeing more physician time for providing direct care. We did not attempt to analyze this hypothesis in the survey since data would be required on the the employment of allied health personnel in solo practice, in nongroup partnerships, and in other practice arrangements as well as in group practice. In this survey, data were merely collected on the number of allied health personnel employed by groups. The distribution of the 65,336 allied health personnel in all types of group practice shows that clerical workers made up the single largest category, representing one-third of total allied health personnel. Registered nurses, licensed practical nurses, and nurses aides combined accounted for another one-third (table 6).

The average number of allied health personnel per physician was 2.3 for all types of group practice, with 2.5 in multispecialty, 1.9 in single specialty, and 2.5 in general practice groups (table 6). Groups in the size category of 100 physicians and over had a relatively high percentage (10.4 percent) of allied health personnel, probably because some of these groups run hospitals or large clinics which require large staffs of such personnel.

\section{Groups With Prepayment Plans}

Information on prepayment was not sought on the questionnaire. However, because of the current interest in prepaid group practice, we believed that a profile of group practice would not be complete without some information on prepaid groups. With the cooperation of the Medical Group Management Association, 88 groups in the survey were identified which pro-
Table 5. Group physicians as a percentage of total physicians engaged in patient care in 1965, by specialty and type of group

\begin{tabular}{|c|c|c|c|}
\hline \multirow[b]{2}{*}{ Specialty } & \multicolumn{3}{|c|}{ Type of group } \\
\hline & Total & $\begin{array}{c}\text { Single } \\
\text { specialty } \\
\text { and general } \\
\text { practice }\end{array}$ & $\begin{array}{l}\text { Multi- } \\
\text { specialty }\end{array}$ \\
\hline Total & 10.9 & 4. 3 & 6. 6 \\
\hline 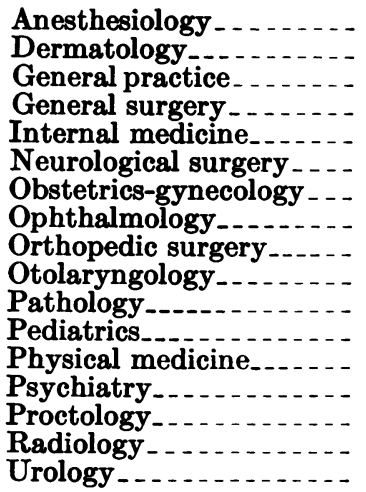 & $\begin{aligned} 26.4 \\
9.7 \\
7.7 \\
10.9 \\
13.7 \\
14.6 \\
14.5 \\
8.8 \\
18.8 \\
11.1 \\
9.2 \\
14.7 \\
9.0 \\
3.8 \\
12.1 \\
27.1 \\
13.9\end{aligned}$ & $\begin{array}{r}23.2 \\
1.3 \\
3.2 \\
1.8 \\
3.3 \\
6.7 \\
5.1 \\
2.4 \\
10.3 \\
2.8 \\
5.6 \\
5.1 \\
2.0 \\
1.3 \\
4.0 \\
17.6 \\
4.8\end{array}$ & $\begin{aligned} \text { 3. } 2 \\
\text { 8. } 3 \\
\text { 4. } 5 \\
9.2 \\
\text { 10. } 4 \\
\text { 7. } 9 \\
\text { 9. } 3 \\
6.3 \\
\text { 8. } 5 \\
\text { 8. } 3 \\
\text { 3. } 6 \\
9.6 \\
\text { 7. } 0 \\
\text { 2. } 6 \\
\text { 8. } 0 \\
\text { 9.5 } \\
\text { 9. } 1\end{aligned}$ \\
\hline
\end{tabular}

vided a significant amount ( 50 percent or more) of care on a prepayment basis. Separate tabulations were made on these groups. Most of the prepaid groups were multispecialty (88.6 percent), and almost all of the physicians in prepaid groups were in multispecialty groups (98.5 percent). The average size of prepaid groups was 39.7 physicians.

Two-thirds of the prepaid groups were in the Middle Atlantic, West North Central, and Pacific Census Divisions. These same three census divisions contained 84.2 percent of the physi-

Table 6. Number of allied health personnel per physician, by type of group and size

\begin{tabular}{|c|c|c|c|c|c|c|}
\hline $\begin{array}{l}\text { Type and size } \\
\text { of group }\end{array}$ & $\begin{array}{c}\text { Total } \\
(\mathrm{N}=65,336)\end{array}$ & $\begin{array}{l}\text { Regis- } \\
\text { tered } \\
\text { nurses }\end{array}$ & $\begin{array}{c}\text { Licensed } \\
\text { practical } \\
\text { nurses and } \\
\text { nurses aides }\end{array}$ & $\begin{array}{l}\text { Laboratory } \\
\text { and X-ray } \\
\text { technicians }\end{array}$ & Clerical & Other \\
\hline $\begin{array}{c}\text { Type } \\
\text { All groups. }\end{array}$ & 2.3 & 0.4 & 0.3 & 0.5 & 0.8 & 0.2 \\
\hline $\begin{array}{l}\text { Single specialty } \\
\text { General practice } \\
\text { Multispecialty }\end{array}$ & $\begin{array}{l}1.9 \\
2.5 \\
2.5\end{array}$ & $\begin{array}{l}.3 \\
.5 \\
.5\end{array}$ & $\begin{array}{l}.2 \\
.6 \\
.4\end{array}$ & $\begin{array}{l}.7 \\
.3 \\
.4\end{array}$ & $\begin{array}{l}.7 \\
.8 \\
.9\end{array}$ & $\begin{array}{l}.1 \\
.3 \\
.3\end{array}$ \\
\hline $\begin{array}{l}3-5 \\
6-15 \\
60-49\end{array}$ & $\begin{array}{l}2.2 \\
2.1 \\
2.3 \\
2.7 \\
\text { 3. } 0 \\
\end{array}$ & $\begin{array}{l}.4 \\
.4 \\
.5 \\
.6 \\
.5 \\
\end{array}$ & $\begin{array}{l}.4 \\
.3 \\
.3 \\
.3 \\
.4\end{array}$ & $\begin{array}{l}.5 \\
.4 \\
.3 \\
.4 \\
.5 \\
\end{array}$ & $\begin{array}{r}.7 \\
.8 \\
.9 \\
1.1 \\
1.2\end{array}$ & $\begin{array}{r}.2 \\
.2 \\
.3 \\
.3 \\
.4\end{array}$ \\
\hline
\end{tabular}


cians in prepaid groups. Only 29 States had prepaid groups. Of these, California, Minnesota, und New York contained 44.3 percent of the prepaid groups and 71.7 percent of the physicians in prepaid groups. Prepaid groups were concentrated in large communities.

Although partnerships were the dominant form of organization for prepaid groups, a lower percentage of prepaid groups were partnerships (60.2 percent) than was true of the total groups in the survey (77.8 percent). On the other hand, a larger percentage of prepaid groups were corporations (12.5 percent) than was true of total groups (8.1 percent).

There were 4,623 allied health personnel in the 88 prepaid groups. Of these 4,623, registered nurses, licensed practical nurses, and nurses aides combined represented 37.2 percent; laboratory and $\mathrm{X}$-ray technicians, 17.4 percent; and clerical and maintenance personnel, 38 percent.

\section{Comparison of Surveys, 1946, 1959, 1965}

Comparison of the Public Health Service group practice surveys of 1946 and 1959 with the AMA survey of 1965 presented some definitional problems. As a result, general practice groups and multispecialty groups had to be combined, and most comparisons were limited to this classification to the exclusion of single specialty groups. Since the 1959 survey conducted by the Public Health Service included groups with fewer than three full-time physicians, comparisons are limited to instances in which data in the 1959 survey were presented by size of group.

The percentage changes mentioned in this section refer to differences between the surveys and do not necessarily provide accurate estimates of the real growth of group practice generally. Reporting errors have accrued on account of the failure to include some groups whose existence was not known at the time the survey was being conducted. This lack of completeness is particularly true of the earlier surveys when recordkeeping was not as comprehensive as it is now.

The total number of groups with three or more full-time physicians increased from 404 in 1946 to 1,546 in 1959 and to 4,289 in 1965. These figures represent an annual average increase of 10.9 percent from 1946 to 1959 and an 18.5 per- cent annual average increase from 1959 to 1965. Single specialty groups increased faster than the other types of groups. In 1946, single specialty groups represented 8.9 percent of total groups. By 1959, this figure was 25.4 percent; by 1965 , it had increased to 50.4 percent.

The 13.9 percent annual average increase in total group physicians from 1959 to 1965 , when compared with the 18.5 percent annual average increase in groups during the period, explains the decrease in the average size of groups from 8.4 physicians per group in 1959 to 6.6 in 1965 . Another indication of the decrease in size is that multispecialty and general practice groups with three or four physicians represented higher percentages of total groups in 1965 than in 1959 , but groups with five or more physicians decreased relative to total groups during the 1959-65 period.

There were several changes in the geographic distribution of groups and group physicians in the periods between the three surveys. The Pacific Census Division, which included 12 percent of multispecialty and general practice groups in 1946, had 14.6 percent of these groups in 1959 and 18.7 percent in 1965. The South Atlantic Division showed similar increases, going from 5.7 percent of multispecialty and general practice groups in 1946 to 8.1 percent in 1959 and 9.5 percent in 1965. The South Atlantic Division also showed a similar trend over the two periods.

There was considerable variation in the annual average percentage increases of multispecialty and general practice groups and group physicians among census divisions from 1959 to 1965. The smallest annual average increase in groups was in the West North Central Division (4.7 percent) ; the largest was in the East North Central Division (15.6 percent). Physicians in multispecialty and general practice groups had the lowest annual average increase in the West North Central Division (5.4 percent) and the highest in the South Atlantic Division (14.5 percent).

The average size of all multispecialty and general practice groups declined from 9.9 physicians in 1959 to 9.1 in 1965 , but the average size of these types of groups in the South Atlantic, East South Central, and West North Central Census Divisions increased during the 1959-65 period. 


\section{PLANNING,}

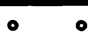

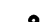

$\circ$

MODEL CITIES STYLE

Planning, model cities style, began in October 1967 for Model Neighborhoods in 75 cities and counties throughout the nation. Following the first planning year, each of the 75 localities produced plans consisting of problem analyses, 5-year forecasts of programs to meet the problems, and first-year action plans to begin the programs.

Key features that encapsulate the model cities concept are local planning and local decision making, meaningful participation by residents of the target (model neighborhood) area of the city, the mandate to innovate, and comprehensiveness in planning.

A good illustration of how the features and the overall concept are working is evident in Denver. This city has ghetto problems which may be considered typical, but presently less severe than those in some of the larger cities. Twelve resident committees, each with the aid (usually nondirective) of local technical consultants, were encouraged to produce a ranked list of problems. Each of these committees functioned in a separate subject area, such as health, welfare, police-community relations, and so forth. Education was divided among three committees-adult education, vocational education, and individualized education, which was concerned with children from kindergarten through 12th grade.

The resident committee on individualized education concluded that the overall problem is underachievement of school children as measured by standard scholastic achievement tests and as compared with children in the rest of the city. In order of priority, beginning with the most important, they listed causes, or subproblems, and proposed solutions in their 5-year plan.

The following are the subproblems listed in descending order of importance: hunger, poor physical health, poor mental health, mental retardation (and other physical and mental handicaps), transportation, teaching, clothing, parent involvement, cultural deprivation, and inequality of educational opportunity.

This list brings to mind several interesting speculations: Would educational or health professionals, working together or separately, have come up with this wide ranging mixture of causes of scholastic underachievement or anything similar to this sequence? On the other hand, it seems doubtful that professionals can argue against this list and its priorities. The collaboration among agencies and individuals which will be necessary to attack these problems (along with continued participation of residents) is as wide ranging as the problems themselves, and could provide, in the microcosm of just one subject area, a challenging test.

This test will surely involve people and organizations who have not thought themselves to be associated with furthering the achievement of school children, as well as those more traditionally considered, at least by the professionals, to be involved.-Ruth E. Dunham, M.D., M.P.H., program director, Health Facilities Planning and Construction Service and HSMHA Model Cities Representative for Region VIII, Health Services and Mental Health Administration, Public Health Service, Denver, Colo. 